\title{
The role of autophagy in Alzheimer's disease
}

\author{
Qian $\mathrm{Li}^{1}$ and Miao Sun ${ }^{2 *}$ \\ ${ }^{1}$ Department of cancer research, Weill Cornell Medical Center, USA \\ ${ }^{2}$ Department of Neuroscience and Cell Biology, Robert Wood Johnson Medical School, Rutgers University, USA
}

\begin{abstract}
Autophagy is a key pathway to clear cellular abnormal protein aggregates, and is essential for protein homeostasis and neuronal health. Several studies have shown autophagy deficits may occur in early stage of Alzheimer's disease (AD). Regarding to Alzheimer's disease, autophagy itself plays an important role in generation and metabolism of $\beta$-amyloid (A $\beta)$, assembling of tau and thus its dysfunction may lead to the progress or aggravate of AD. By considering all published evidences, autophagy may be considered as a new target for developing AD targeted drugs. So far, a number of mammalian target of rapamycin (mTOR)-dependent and independent autophagy modulators have been identified to have positive effects in $\mathrm{AD}$ treatment. In this review, we summarized the latest progress supporting the role for autophagy deficits in $\mathrm{AD}$, and the potential therapeutic effects of autophagy modulators in AD.
\end{abstract}

Acronyms: AD: Alzheimer's disease, $A \beta$ : $\beta$-amyloid, mTOR: mammalian target of rapamycin, CMA: chaperone-mediated autophagy, ROS: reactive oxygen species, mTORC1: mammalian target of rapamycin complex 1, ULK: Unc-51-like kinase, LC3B: light chain 3 beta, PE: phosphatidylethanolamine, UVRAG: UV radiation resistance-associated gene protein, AMPK: AMP-activated protein kinase, DFCP-1: Double-FYVE Containing Protein 1, PI3P: Phosphatidylinositol 3-Phosphate, AVs: autophagic vacuoles, SAD: sporadic AD, FAD: familial AD, apoE4: Apolipoprotein E4, APP: amyloid precursor protein, PS: presenilin, GSK-3: Glycogen synthase kinase-3, hsc 70: heat shock cognate protein of 70KD, LAMP-2A: lysosomal-associated membrane protein 2A, lys-hsc70: Lysosomeresident form of hsc70, APP-CTFs: amyloid precursor protein cleaved C-terminal fragment, AEL: autophagy-endosomal-lysosomal, PTX: Picrotoxin, UPS: ubiquitin-proteasome system, Nrf2: nuclear factor erythroid-2-related factor 2, PICALM: Phosphatidylinositol binding clathrin assembly protein, SNAREs: Soluble NSF Attachment protein Receptors

\section{Introduction}

$\mathrm{AD}$, which is the most prevalent and common neurodegenerative disease for elder people, is characterized by deficiency in memory and cognitive functions. The predominant pathological hallmarks of $\mathrm{AD}$ are the generation of $A \beta$ plaques in specific brain areas, formation of neurofibrillary tangles in neurons axons and progressive loss of dendrite synapses and the eventually neuron apoptosis [1,2]. Although the etiology and molecular mechanisms underlying these pathological changes are not completely elucidated, recent studies have indicated deficiencies in autophagy-lysosome pathway, which is an important system to eliminate misfolded proteins or damaged organelles, are likely to precede the formation of $A \beta$ plaques or neurofibrillary tangles [3]. Until now, three kinds of autophagy: macroautophagy, microautophagy, and chaperone-mediated autophagy (CMA), have been identified in mammalian cells. Among them, macroautophagy is get best studied and considered most relevant to $\mathrm{AD}, \mathrm{CMA}$ has also been indicated by some reports to play a role in AD. To make it simple, hereon we will refer macroautophagy as "autophagy". In the present review, we will begin with the autophagy physiological machinery, evidence of autophagy malfunction in $\mathrm{AD}$, relationship between autophagy dysfunction and $\mathrm{AD}$-related pathology, and finally focus on the therapeutic potential of autophagy modulators.

\section{Materials and methods}

We used "Alzheimer's disease" and "autophagy" as keywords to search PubMed and review the related papers.

\section{Autophagy machinery}

Autophagy biogenesis includes multiple stages: phagophore membrane isolation, phagophore elongation and engulf of random cytoplasmic content, autophagosome maturation and fusion with lysosome [4]. Generally, the activation of autophagy is largely depended on cellular starving condition [5,6], such as low amino acids or glucose concentration. However, recent studies have also proven autophagy could be stimulated by diverse factors, such as reactive oxygen species (ROS) [7], hypoxia impairments [8], subcellular organelle damages [9] and protein aggregation [10]. However, in all its regulators, the mammalian target of rapamycin complex 1(mTORC1) has been studied most thoroughly and considered to play a key role in autophagy biogenesis.

In amino acid depletion environment, mTORC1 complex is in rest situation and distributed freely in cytoplasm. At that stage, mTORC1 complex cannot regulate autophagy initiation. However, in nutrition enrichment conditions, the lysosomal amino acid concentration will be largely increased, which will in turn activate v-ATPase on the lysosome membrane. v-ATPase is a lysosome membrane multimeric channel protein with a majorly function as ATPase and $\mathrm{H}^{+}$channel, meanwhile,

Correspondence to: Miao sun, Department of Neuroscience and cell biology, RWJMS- Rutgers, 675 hoes lane west, Piscataway, NJ, USA, 08854, Email: sunm2@ rwjms.rutgers.edu

Key words: autophagy, $\beta$-amyloid, tau, Alzheimer's disease

Received: June 02, 2017; Accepted: July 21, 2017; Published: July 24, 2017 
it also functions as a sensor for lysosomal amino acid concentration. After sensing the increase of amino acid concentration, v-ATPase and its binding partner, Regulator, would both change their conformations and thus activate downstream signal molecule: RagA/B, by converting which conformation from GDP-bound to GTP-bound. Activated $\mathrm{RagA} / \mathrm{B}$ will then recruit free mTORC1 onto lysosome membrane and facilitate another small GTPase, Rheb, to activate mTORC1 on lysosome membrane [11-13]. After mTORC1 activation, it will negatively control autophagy genesis by blocking Unc-51-like kinase (ULK) $1 / 2$ complex, which is an important inducer for autophagy by regulating Beclin1-VPS34 complex [14]. On the other hand, activated ULK1/2 could also activate microtubule-associated protein 1 light chain 3 beta (LC3B) by phosphatidylethanolamine (PE) modification [15]. LC3 is important for phagophore elongation and autophagosome formation [16]. Furthermore, activated mTORC1 could also inhibit autophagosome fusion with lysosome by phosphorylating UV radiation resistance-associated gene protein (UVRAG) [17] and thus keeping autophagosome out of lysosome and blocking its maturation. Therefore, activated mTORC1 could inhibit autophagy bio-genesis at all required stages, and inhibition of mTOR pathway by either pharmacological compounds such as rapamycin or activation of AMPactivated protein kinase (AMPK) [18] could facilitate autophagy process.

\section{Autophagy in neuronal cells}

Autophagy is an essential pathway to maintain metabolism homeostatic in neurons [19]. Similar to other types of cells, with aging process, neuronal cell will also accumulate intracellular toxicant or damaged organelles such as mitochondria that must to be eliminated by autophagy to avoid potential cellular stress [20]. However, with its post-mitotic characters, neurons cannot dilute toxic substance by mitosis. So autophagy dependent protein/organelles clearance would be more important in neurons.

Neurons are characterized by their highly polarized axons and dendritic compartments. Through the connections between elongated axons and multi-directional dendrites, neurons could make to communicate to another neuron with distances many times longer than their cell soma and thus connect to each other's from long distance with minimized cell number [21].

Autophagosomes in neurons are majorly formed at axonal tips and gradually matured when they are retrograde transporting along axons to cell somas [19]. There is another evidence indicated autophagosome may form in the middle part of axon in order to clear damaged mitochondria [22]. Furthermore, some research also indicated autophagosome axonal distal biogenesis might correlate with synaptic function as well [23]. The first step of autophagosome biogenesis at axon tip is recruiting Atg13 and Atg5 to Double-FYVE Containing Protein 1 (DFCP-1). DFCP-1 is a Phosphatidylinositol 3-Phosphate (PI3P) enriched, omega-shaped ER structure that serves as a platform for autophagosome biogenesis [24]. Then within 4-6 minutes, lipidated LC3 will be incorporated into the developing of autophagosome [25]. Autophagy induction is more efficient in younger neurons [26], as the expression amount of autophagy induction related proteins such as beclin-1, Atg5 and Atg7 will decline with age [27,28], which may potentially contributing to the late onset of many neurodegenerative diseases [29] including AD.

\section{Autophagy malfunction in AD}

There is substantial evidence that dysregulation of autophagy is actually occurred in both $\mathrm{AD}$ animal models and $\mathrm{AD}$ patients. As early as 1967, Suzuki had found a large amount of abnormal aggregated tau protein and subcellular vesicles accumulated in the dystrophic or swollen neurites in $\mathrm{AD}$ patient brains [30], but the identity of these vesicles was unclear until 2005, when Nixon's group found immature autophagic vacuoles (AVs) accumulated in dystrophic neuritis in $\mathrm{AD}$ brains by using immunogold labeling and electron microscopy [31]. This is the first direct evidence showed autophagy deficiency was involved in $\mathrm{AD}$. In the same year, similar results from PS-1/APP double transgenic mice [32] also showed AVs would be accumulated in neuronal dendrites and soma even before $A \beta$ plaques appeared compared to age-matched controls. In addition to these direct ultramicroscopic results, several autophagy-related proteins have also been found down-regulated in $\mathrm{AD}$ process. For example, Rubinsztein reported decreased expression of some lysosomal protease in the early phase of $\mathrm{AD}$ patients [33]. A recent study has found down regulation of some autophagy-related genes: atg1, atg8a, and atg18 in aged Drosophila melanogaster compare with younger controls. Furthermore, the same study also found reduced autophagy activity and hyper-generation of $A \beta$ were both considered to correlate with late-onset neuronal dysfunction and $\mathrm{AD}$ phenotype [34], indicating that reduction of autophagy-related gene expression with age may contribute to late onset $\mathrm{AD}$.

Two types of $\mathrm{AD}$ has been identified to date: sporadic $\mathrm{AD}$ (SAD, also known as late-onset $\mathrm{AD}$ ), and familial $\mathrm{AD}$ (FAD, also known as early-onset $\mathrm{AD}$ ). Although little is known about the cause of late onset $\mathrm{AD}$, it is widely accepted now that both genetic and environmental factors would contribute to this pathogenesis. Apolipoprotein E4 (apoE4), a major genetic risk factor for SAD, has been found can cause autophagy malfunction. Results from ApoE4 transgenic mice showed ApoE4 overexpression could lead to A $\beta 42$ hyper-generation in lysosome, which could finally lead to hippocampus neurons death [35]. In addition, ApoE 4 could potentiate $A \beta$ peptides induced lysosomal contains leakage and cell apoptosis in Neuro-2a cells [36]. Taken together, these studies indicated ApoE4 and $\mathrm{A} \beta$ may work in concert to increase the susceptibility of lysosomal membranes disruption, release of lysosomal enzymes, and hence neuronal degeneration [36].

Regarding to FAD, at least three genes, amyloid precursor protein (APP), presenilin-1 and -2(PS-1 and PS-2), have been identified as causative genes so far. FAD is caused by mutation in at least one of the three genes [37]. Research has found wildtype PS-1, but not mutation forms, is crucial for acidification of lysosome by regulating distribution of v-ATPase, and thus contributes to autophagy degradation in a gamma-secretase independent way [38]. Meanwhile, hyper-activation of Glycogen synthase kinase-3 (GSK-3), which is also a high-risk factor for $\mathrm{AD}$, could interfere lysosome acidification via similar mechanism as PS-1 [39]. These investigations suggested that autophagy malfunction is involved in FAD, while the mechanism(s) is still not clear.

Proper formation and degradation of autophagosome is critical for normal autophagic flux. In healthy neurons, low basal autophagic activity was detected because of the quick subsequent degradation of autophagosome by lysosome. In hippocampus neurons of AD mice, abnormal accumulation of immature AVs in axon was observed before synaptic and neuronal loss [40]. However, as either autophagosome axonal trafficking deficiency or insufficient lysosome acidification could cause AVs accumulation in axon, the actual mechanisms underlying autophagy dysfunction in $\mathrm{AD}$ is still need further investigate. It is also a debate whether dysfunction of autophogy is the cause or result of AD. Reports to date usually show some controversies [41-43]. Many factors may lead to these differences, such as different animal models, cellular models, and experimental paradigms. Also, the different model systems 
are likely represented of different particular stages of $\mathrm{AD}$ pathogenic process.

Another autophagy form is CMA. CMA is distinct from macroautophagy as CMA degradation pathway will accurately degrade certain proteins without engulf process and most of its degradation target proteins would be cytoplasm soluble proteins. This selective degradation pathway also contributes to maintenance of cellular homeostasis particularly under stress conditions together with other types of autophagy [44-47]. In the process of CMA mediated degradation, targeted protein will first be recognized and bind by a cytosolic chaperone, heat shock cognate protein of 70KD (hsc 70). Most of hsc 70 targeting proteins share a reserved KFERQ sequence [48]. After binding with cytoplasmic hsc70, the target proteins will be unfold and delivered onto lysosome membrane. At lysosome membrane, lysosomal-associated membrane protein 2A (LAMP-2A) will form a transient multimeric channel to allow target proteins to translocate through lysosome membrane. Lysosome-resident form of hsc70 (lys-hsc70) in lysosome luminal side will also assist this process [49-52]. It has been considered that the number of lys-hsc70 positive lysosome would decide the speed of CMA mediated degradation under physiology condition.

Similar to macroautophagy, CMA is also considered to be related with neurodegeneration diseases such as $\mathrm{AD}$ and $\mathrm{PD}$. It has been found CMA plays an important role in both Tau tangles formation and $\mathrm{A} \beta$ peptides generation and its activity is impaired in aged cells [53]. It has been found although Tau protein contains CMA recognizing motif in its sequence, trace amount of wild type Tau is indeed degraded by CMA. Generally, for totally degradation, Tau will be cleaved in cytoplasm firstly, and then the C-terminal part tanslocate into lysosome luminal for second and third cleavage [54]. Either autophagy or CMA process will both assist C-ter Tau get through lysosomal membrane. However, in certain Tau mutations, the first cleavage may happen in wrong amino acid position. After this cleavage, although remaining C-ter truncated Tau could still be recognized by hsc70 and recruited onto lysosome membrane, it cannot translocate into lysosome luminal efficiently, and thus resulting in accumulation of truncated Tau on lysosome membrane. Those undigested truncated Tau will then form oligomeric structures on the lysosomal membrane, gradually disrupt lysosomal membrane and finally cause leakage of lysosomal enzymes [53].

Another recent study has found APP also has KFERQ motif which could be recognized by hsc70. Deletion of this sequence will block APP degradation in lysosome and correspondently increase its secretase cleavage products. However, APP could still bind to hsc70 even without this KFERQ motif [55].

\section{Autophagy dysfunction and AD-related pathology}

To date, $A \beta$ plaques and neurofibrillary tangles are still be considered as two major neuro-pathological changes in AD patient's brain. Emerging evidence has demonstrated complicated interactions among autophagy, $A \beta$, and tau, which may contribute to the progress of $\mathrm{AD}$.

Autophagy plays an important role in the metabolism of A $\beta$. First of all, autophagy is believed to be another major $A \beta$ clearance pathway besides those well-known $A \beta$ degradation enzymes [56]. Autophagy facilitates the degradation and clearance of APP [57] as well as all APP cleavage products including A $\beta$ [47,58], and APP-CTFs (amyloid precursor protein cleaved C-terminal fragment) [59]. In microglia, $\mathrm{A} \beta$ has also been found to be degraded by autophagy through the autophagy receptor optineurin [60].
Secondly, autophagy-lysosome degradation system, which is considered important for $A \beta$ degradation under multiple physiological conditions, has been demonstrated to be a novel way for $A \beta$ production under pathological condition or in aging process [32]. Although $A \beta$ is thought to be produced in endoplasmic reticulum, lysosome, and Golgi apparatus, emerging studies have provided evidence that $A \beta$ generation may also happened in autophagic vacuoles [61]. Thus, accumulated immature autophagic vacuoles found in AD brains and in APP/PS1 transgenic mice may present a novel source for $A \beta$ generation [31]. Immunohistochemistry staining also showed $A \beta 42$ were existed in AEL (autophagy-endosomal-lysosomal) vesicles in Drosophila neurons [62]. Another study applied on neuron showed that although APP and its processing enzyme BACE1 should be separated into distinct vesicles under normal condition, they showed strong co-localization and co-trafficking into autophagy-lssosome pathways under glycine/ NMDA-receptor agonist /K+ or GABA antagonist Picrotoxin (PTX) stimulations [63]. This result indicated under some certain pathological conditions, the convergence of APP and BACE1 in autophagosomes may perform as novel place for $A \beta$ generation.

Third, autophagy is also involved in the secretion of $A \beta$. Recent findings support that autophagy may responsible for extracellular released $A \beta$. Measurement of extracellular $A \beta$ in autophagy-deficient mice revealed that the $A \beta$ secretion was reduced by $90 \%$, while restoration of autophagy enhanced $A \beta$ secretion to normal levels [64]. There is another recent work has also found in ATG7 knockdown mice, the secretion $A \beta$ was largely reduced, which was accompanied by a significant intracellular $A \beta$ accumulation [65].

On the other side, $A \beta$ peptides could also regulate autophagy activity. $A \beta 40$ in vascular could induce autophagy in endothelial cell and impair neurovascular regeneration [66]. Further study showed $A \beta$ induced formation of AVs was regulated through the RAGE-calciumCaMKK $\beta$-AMPK pathway [58].

When it comes to the case of tau, although ubiquitin-proteasome system (UPS) was still considered to be the major pathway for tau turnover, recent studies suggested autophagy may perform as another effective degradation route for Tau. A number of studies have demonstrated that dysfunction of autophagy-lysosome system leads to the formation of tau oligomers and insoluble aggregates, meanwhile activates autophagy could alleviate this aggregation $[67,68]$. Moreover, autophagy mayaffect Tau phosphorylation status. Hyperphosphorylated tau was found to be accumulated in brains of autophagy deficient mice [69], and this Hyperphosphorylated-tau accumulation will be largely reduced after autophagy was restored. Researchers have found autophagic degradation of tau is regulated by nuclear factor erythroid2-related factor 2 (Nrf2)-mediated activation of the autophagy receptor NDP52 [70]. Furthermore, Phosphatidylinositol binding clathrin assembly protein (PICALM, also known as CALM) could also regulate Tau degradation by modulating SNAREs (Soluble NSF Attachment protein Receptors) endosytosis, which is critical for tau autophagy clearance [71]. On the other hand, hyperphosphorylation of tau may result in autophagy dysfunction [72,73]. Tau is well-identified to facilitate the assembly and stabilization of microtubule, which is critical for autophagosome retrograde trafficking and maturation to fuse with lysosome. On contrast, hyperphosphorylated tau could lead to the instability and disassemble of microtubule cytoskeleton, which could subsequently inhibit autophagysome retrograde trafficking and thus accumulate immature autophagysomes in axons.

Axonal transport is an essential process required to maintain neuronal homeostasis. Impaired axonal transport can lead to axon 
degeneration and has been found in many neurodegenerative diseases including $\mathrm{AD}$. In mammalian cells, newly formed autophagosomes move along with microtubule tracks [74] and during this process, autophagosomes engulf long-lived protein, misfolded protein or damaged organelles such as mitochondria, subsequently degrade them after fused with lysosome. Deficits in axonal transport usually result in accumulation of large amounts of autophagosome. Axonal dystrophic neurites arising from neurofibrillary tangles could be easily detected in hippocampus CA3 and CA1regions [75].

Years of pathological examination in $\mathrm{AD}$ brains have yielded many descriptions of abnormal axonal transport in both early and late phase of $\mathrm{AD}$ [76]. Meanwhile, the phosphorylated tau level affects axonal transport and degradation [77]. These data supported that abnormal protein aggregates disrupt axons, thereby autophagosomes couldn't transport to cytoplasm and thus failed to fuse with lysosomes. In contrast to this, some other studies gave opposite viewpoints that lysosomal protease abnormalities are the causative factor of axonal degeneration [78]. However, the mechanism(s) underlying this transport disruption isn't clear.

\section{Concluding remarks and future perspectives}

Although the etiology of $\mathrm{AD}$ remains unclear, and many factors including genetic mutation, environmental factors, imbalance of energy metabolism and heavy metal ion $[79,80]$ seem to contribute to the etiology of $\mathrm{AD}$, emerging advances regarding to autophagy have indicated its role as a protective factor in the early phase of $\mathrm{AD}$, but an evil player in the late phase. Autophagy can influence the generation, secretion and clearance of $A \beta$, and it will also influence the phosphorylation status and clearance of tau. Thus, chemical modulators of autophagy as well as gene therapy targeting autophagy related proteins offer great potential for the treatment of $\mathrm{AD}$. A number of mTOR-dependent and independent autophagy modulators have been demonstrated to have positive effects in $\mathrm{AD}$ animal models and patients. However, a more throughout understanding of autophagy malfunction in $\mathrm{AD}$, as well as brain pharmacokinetics of autophagy modulators will be critical for designing new experiments with appropriate drug doses in any future clinical trials for $\mathrm{AD}$.

\section{References}

1. Ingelsson M, Fukumoto H, Newell KL, Growdon JH, Hedley-Whyte ET, et al. (2004) Early Abeta accumulation and progressive synaptic loss, gliosis, and tangle formation in AD brain. Neurology 62: 925-931. [Crossref]

2. Li Q, Liu Y, Sun M (2016) Autophagy and Alzheimer's Disease. Cellular and molecular neurobiology 1-12. [Crossref]

3. Correia SC, Resende R, Moreira PI, Pereira CM (2015) Alzheimer's disease-related misfolded proteins and dysfunctional organelles on autophagy menu. DNA Cell Biol 34: 261-273. [Crossref]

4. Lee KM, Hwang SK, Lee JA (2013) Neuronal autophagy and neurodevelopmental disorders. Exp Neurobiol 22: 133-142. [Crossref]

5. Kuma A, Hatano M, Matsui M, Yamamoto A, Nakaya H, et al. (2004) The role of autophagy during the early neonatal starvation period. Nature 432: 1032-1036. [Crossref]

6. Mizushima N, Yamamoto A, Matsui M, Yoshimori T, Ohsumi Y (2004) In vivo analysis of autophagy in response to nutrient starvation using transgenic mice expressing a fluorescent autophagosome marker. Mol Biol Cell 15: 1101-1111. [Crossref]

7. Scherz-Shouval R, Shvets E, Fass E, Shorer H, Gil L, et al. (2007) Reactive oxygen species are essential for autophagy and specifically regulate the activity of Atg4. EMBO J 26: 1749-1760. [Crossref]

8. Mazure NM, Pouysségur J (2010) Hypoxia-induced autophagy: cell death or cell survival? Curr Opin Cell Biol 22: 177-180. [Crossref]
9. Song Z, Zhao D, Yang L (2013) Molecular mechanisms of neurodegeneration mediated by dysfunctional subcellular organelles in transmissible spongiform encephalopathies. Acta Biochim Biophys Sin (Shanghai) 45: 452-464. [Crossref]

10. Liu C, Gao Y, Barrett J, Hu B (2010) Autophagy and protein aggregation after brain ischemia. J Neurochem 115: 68-78. [Crossref]

11. Zoncu R, Bar-Peled L, Efeyan A, Wang S, Sancak Y, et al. (2011) mTORC1 senses lysosomal amino acids through an inside-out mechanism that requires the vacuolar $\mathrm{H}(+)$-ATPase. Science 334: 678-683. [Crossref]

12. Jewell JL, Russell RC, Guan KL (2013) Amino acid signalling upstream of mTOR. Nat Rev Mol Cell Biol 14: 133-139. [Crossref]

13. Yadav RB, Burgos P, Parker AW, Iadevaia V, Proud CG, et al. (2013) mTOR direct interactions with Rheb-GTPase and raptor: sub-cellular localization using fluorescence lifetime imaging. BMC Cell Biol 14: 3. [Crossref]

14. Russell RC, Tian Y, Yuan H, Park HW, Chang YY, et al. (2013) ULK1 induces autophagy by phosphorylating Beclin-1 and activating VPS34 lipid kinase. Nat Cell Biol 15: 741-750. [Crossref]

15. Fujita N, Itoh T, Omori H, Fukuda M, Noda T, et al. (2008) The Atg16L complex specifies the site of LC3 lipidation for membrane biogenesis in autophagy. Mol Biol Cell 19: 2092-2100. [Crossref]

16. Bernard A, Klionsky DJ (2014) Defining the membrane precursor supporting the nucleation of the phagophore. Autophagy 10:1-2. [Crossref]

17. Kim YM, Jung CH, Seo M, Kim EK, Park JM, et al. (2015) mTORC1 phosphorylates UVRAG to negatively regulate autophagosome and endosome maturation. Mol Cell 57: 207-218. [Crossref]

18. Wu T, Wang MC, Jing L, Liu ZY, Guo H, et al. (2015) Autophagy facilitates lung adenocarcinoma resistance to cisplatin treatment by activation of AMPK $/ \mathrm{mTOR}$ signaling pathway. Drug Des Devel Ther 9: 6421-6431. [Crossref]

19. Maday S, Wallace KE, Holzbaur EL (2012) Autophagosomes initiate distally and mature during transport toward the cell soma in primary neurons. J Cell Biol 196 407-417. [Crossref]

20. Mariño G, Madeo F, Kroemer G (2011) Autophagy for tissue homeostasis and neuroprotection. Curr Opin Cell Biol 23: 198-206. [Crossref]

21. Bullmore E, Sporns O (2012) The economy of brain network organization. Nat Rev Neurosci 13: 336-349. [Crossref]

22. Ashrafi G, Schlehe JS, LaVoie MJ, Schwarz TL (2014) Mitophagy of damaged mitochondria occurs locally in distal neuronal axons and requires PINK1 and Parkin. $J$ Cell Biol 206: 655-670. [Crossref]

23. Wang T, Martin S, Papadopulos A, Harper CB, Mavlyutov TA, et al. (2015) Control of autophagosome axonal retrograde flux by presynaptic activity unveiled using botulinum neurotoxin type a. J Neurosci 35: 6179-6194. [Crossref]

24. Maday S, Holzbaur EL (2014) Autophagosome biogenesis in primary neurons follows an ordered and spatially regulated pathway. Dev Cell 30: 71-85. [Crossref]

25. Maday S, Holzbaur EL (2012) Autophagosome assembly and cargo capture in the distal axon. Autophagy 8: 858-860. [Crossref]

26. Boland B, Kumar A, Lee S, Platt FM, Wegiel J, et al. (2008) Autophagy induction and autophagosome clearance in neurons: relationship to autophagic pathology in Alzheimer's disease. J Neurosci 28: 6926-6937. [Crossref]

27. Lipinski MM, Zheng B, Lu T, Yan Z, Py BF, et al. (2010) Genome-wide analysi reveals mechanisms modulating autophagy in normal brain aging and in Alzheimer's disease. Proc Natl Acad Sci U S A 107: 14164-14169. [Crossref]

28. Shibata M, Lu T, Furuya T, Degterev A, Mizushima N, et al. (2006) Regulation of intracellular accumulation of mutant Huntingtin by Beclin 1. J Biol Chem 281: 1447414485. [Crossref]

29. Rubinsztein DC, Mariño G, Kroemer G (2011) Autophagy and aging. Cell 146: 682695. [Crossref]

30. Suzuki K, Terry RD (1967) Fine structural localization of acid phosphatase in senile plaques in Alzheimer's presenile dementia. Acta Neuropathol 8: 276-284. [Crossref]

31. Nixon RA, Wegiel J, Kumar A, Yu WH, Peterhoff C, et al. (2005) Extensive involvement of autophagy in Alzheimer disease: an immuno - electron microscopy study. JNeuropathol Exp Neurol 64: 113-122. [Crossref]

32. Yu WH, Cuervo AM, Kumar A, Peterhoff CM, Schmidt SD, et al. (2005) Macroautophagy: a novel beta-amyloid peptide-generating pathway activated in Alzheimer's disease. J Cell Biol 171: 87-98. [Crossref] 
33. Rubinsztein DC, DiFiglia M, Heintz N, Nixon RA, Qin ZH, et al. (2005) Autophagy and its possible roles in nervous system diseases, damage and repair. Autophagy 1: 1122. [Crossref]

34. Omata Y, Lim YM, Akao Y, Tsuda L (2014) Age-induced reduction of autophagyrelated gene expression is associated with onset of Alzheimer's disease. Am J Neurodegener Dis 3: 134-142. [Crossref]

35. Belinson H, Lev D, Masliah E, Michaelson DM (2008) Activation of the amyloid cascade in apolipoprotein E4 transgenic mice induces lysosomal activation and neurodegeneration resulting in marked cognitive deficits. J Neurosci 28: 4690-4701. [Crossref]

36. Ji ZS, Müllendorff K, Cheng IH, Miranda RD, Huang Y, et al. (2006) Reactivity of apolipoprotein E4 and amyloid beta peptide: lysosomal stability and neurodegeneration. J Biol Chem 281: 2683-2692. [Crossref]

37. Tang YP, Gershon ES (2003) Genetic studies in Alzheimer's disease. Dialogues Clin Neurosci 5: 17-26. [Crossref]

38. Lee JH, Yu WH, Kumar A, Lee S, Mohan PS, et al. (2010) Lysosomal proteolysis and autophagy require presenilin 1 and are disrupted by Alzheimer-related PS1 mutations. Cell 141: 1146-1158. [Crossref]

39. Avrahami L, Farfara D, Shaham Kol M, Vassar R, Frenkel D, et al. (2013) Inhibition of glycogen synthase kinase-3 ameliorates ?-amyloid pathology and restores lysosomal acidification and mammalian target of rapamycin activity in the Alzheimer disease mouse model: in vivo and in vitro studies. J Biol Chem 288: 1295-1306. [Crossref]

40. Sanchez-Varo R, Trujillo-Estrada L, Sanchez-Mejias E, Torres M, Baglietto-Vargas D, et al. (2012) Abnormal accumulation of autophagic vesicles correlates with axonal and synaptic pathology in young Alzheimer's mice hippocampus. Acta Neuropathol 123 : 53-70. [Crossref]

41. Peric A, Annaert W (2015) Early etiology of Alzheimer's disease: tipping the balance toward autophagy or endosomal dysfunction? Acta Neuropathol 129: 363-381. [Crossref]

42. Cho SJ, Yun SM, Jo C, Lee DH, Choi KJ, et al. (2015) SUMO1 promotes $\mathrm{AI}^{2}$ production via the modulation of autophagy. Autophagy 11: 100-112. [Crossref]

43. Lee JK, Jin HK, Park MH, Kim BR, Lee PH, et al. (2014) Acid sphingomyelinase modulates the autophagic process by controlling lysosomal biogenesis inAlzheimer's disease. J Exp Med 211: 1551-1570. [Crossref]

44. Cuervo AM (2010) Chaperone-mediated autophagy: selectivity pays off. Trends Endocrinol Metab 21: 142-150. [Crossref]

45. Dice JF (2007) Chaperone-mediated autophagy. Autophagy 3: 295-299. [Crossref]

46. Kaushik S, Cuervo AM (2012) Chaperone-mediated autophagy: a unique way to enter the lysosome world. Trends Cell Biol 22: 407-417. [Crossref]

47. Sun M, Asghar SZ, Zhang H (2016) The polarity protein Par3 regulates APP trafficking and processing through the endocytic adaptor protein Numb. Neurobiology of disease 93: 1-11. [Crossref]

48. Chiang HL, Terlecky SR, Plant CP, Dice JF (1989) A role for a 70-kilodalton heat shock protein in lysosomal degradation of intracellular proteins. Science 246: 382-385. [Crossref]

49. Cuervo AM, Dice JF (1996) A receptor for the selective uptake and degradation of proteins by lysosomes. Science 273: 501-503. [Crossref]

50. Cuervo AM, Dice JF, Knecht E (1997) A population of rat liver lysosomes responsible for the selective uptake and degradation of cytosolic proteins. J Biol Chem 272: 56065615. [Crossref]

51. Agarraberes FA, Terlecky SR, Dice JF (1997) An intralysosomal hsp70 is required for a selective pathway of lysosomal protein degradation. J Cell Biol 137: 825-834. [Crossref]

52. Li Qian, Miao Sun (2012) "Effects of potassium ion channels in term pregnant myometrium." Journal of Obstetrics and Gynaecology Research 38: 479-479. [Crossref]

53. Koga H, Cuervo AM (2011) Chaperone-mediated autophagy dysfunction in the pathogenesis of neurodegeneration. Neurobiol Dis 43: 29-37. [Crossref]

54. Wang Y, Martinez-Vicente M, Krüger U, Kaushik S, Wong E, et al. (2009) Tau fragmentation, aggregation and clearance: the dual role of lysosomal processing. Hum Mol Genet 18: 4153-4170. [Crossref]

55. Park JS, Kim DH, Yoon SY (2016) Regulation of amyloid precursor protein processing by its KFERQ motif. BMB Rep 49: 337-342. [Crossref]
56. Miners JS, Baig S, Palmer J, Palmer LE, Kehoe PG, et al. (2008) Abeta-degrading enzymes in Alzheimer's disease. Brain Pathol 18: 240-252. [Crossref]

57. Zhou F, van Laar T, Huang H, Zhang L (2011) APP and APLP1 are degraded through autophagy in response to proteasome inhibition in neuronal cells. Protein Cell 2: 377 383. [Crossref]

58. Son SM, Jung ES, Shin HJ, Byun J, Mook-Jung I (2012) A $\hat{I}^{2}$-induced formation of autophagosomes is mediated by RAGE-CaMKK $\hat{I}^{2}$-AMPK signaling. Neurobiol Aging 33: 1006. [Crossref]

59. Tian Y, Chang JC, Greengard P, Flajolet M (2014) The convergence of endosoma and autophagosomal pathways: implications for APP-CTF degradation. Autophagy 10: 694-696. [Crossref]

60. Cho MH, Cho K, Kang HJ, Jeon EY, Kim HS, et al. (2014) Autophagy in microglia degrades extracellular $\hat{\mathrm{I}}^{2}$-amyloid fibrils and regulates the NLRP3 inflammasome. Autophagy 10: 1761-1775. [Crossref]

61. Mizushima N (2005) A(beta) generation in autophagic vacuoles. J Cell Biol 171: 1517. [Crossref]

62. Ling D, Magallanes M, Salvaterra PM (2014) Accumulation of amyloid-like A $\beta 1-42$ in AEL (autophagy-endosomal-lysosomal) vesicles: potential implications for plaque biogenesis. ASN Neuro 6: e00139. [Crossref]

63. Das U, Scott DA, Ganguly A, Koo EH, Tang Y, et al. (2013) Activity-induced convergence of APP and BACE-1 in acidic microdomains via an endocytosisdependent pathway. Neuron 79: 447-460. [Crossref]

64. Nilsson P, Saido TC (2014) Dual roles for autophagy: degradation and secretion of Alzheimer's disease $\mathrm{AI}^{2}$ peptide. Bioessays 36: 570-578. [Crossref]

65. Nilsson P, Sekiguchi M, Akagi T, Izumi S, Komori T, et al. (2015) Autophagy-related protein 7 deficiency in amyloid $\hat{\mathrm{I}}^{2}\left(\mathrm{~A}^{2}\right)$ precursor protein transgenic mice decreases $\mathrm{A}^{2}{ }^{2}$ in the multivesicular bodies and induces $\mathrm{A}^{2}$ accumulation in the Golgi. $\mathrm{Am} \mathrm{J}$ Pathol 185: 305-313. [Crossref]

66. Hayashi S, Sato N, Yamamoto A, Ikegame Y, Nakashima S, et al. (2009) Alzheime disease-associated peptide, amyloid $\beta 40$, inhibits vascular regeneration with induction of endothelial autophagy. Arterioscler Thromb Vasc Biol 29: 1909-1915. [Crossref]

67. Hamano T, Gendron TF, Causevic E, Yen SH, Lin WL, et al. (2008) Autophagiclysosomal perturbation enhances tau aggregation in transfectants with induced wildtype tau expression. Eur J Neurosci 27: 1119-1130. [Crossref]

68. Congdon EE, Wu JW, Myeku N, Figueroa YH, Herman M, et al. (2012) Methylthioninium chloride (methylene blue) induces autophagy and attenuate tauopathy in vitro and in vivo. Autophagy 8: 609-622. [Crossref]

69. Inoue K, Rispoli J, Kaphzan H, Klann E, Chen EI, et al. (2012) Macroautophagy deficiency mediates age-dependent neurodegeneration through a phospho-tau pathway. Mol Neurodegener 7: 48. [Crossref]

70. Jo C, Gundemir S, Pritchard S, Jin YN, Rahman I, et al. (2014) Nrf2 reduces levels of phosphorylated tau protein by inducing autophagy adaptor protein NDP52. Nat Commun 5: 3496. [Crossref]

71. Moreau K, Fleming A, Imarisio S, Lopez Ramirez A, Mercer JL, et al. (2014) PICALM modulates autophagy activity and tau accumulation. Nat Commun 5: 4998. [Crossref]

72. Lim F, Hernández F, Lucas JJ, Gómez-Ramos P, Morán MA, et al. (2001) FTDP-17 mutations in tau transgenic mice provoke lysosomal abnormalities and Tau filaments in forebrain. Mol Cell Neurosci 18: 702-714. [Crossref]

73. Lin WL, Lewis J, Yen SH, Hutton M, Dickson DW (2003) Ultrastructural neuronal pathology in transgenic mice expressing mutant (P301L) human tau. $J$ Neurocytol 32 1091-105. [Crossref]

74. Monastyrska I, Rieter E, Klionsky DJ, Reggiori F (2009) Multiple roles of the cytoskeleton in autophagy. Biol Rev Camb Philos Soc 84: 431-448. [Crossref]

75. Su JH, Cummings BJ, Cotman CW (1993) Identification and distribution of axonal dystrophic neurites in Alzheimer's disease. Brain Res 625: 228-237. [Crossref]

76. Bell KF, Claudio Cuello A (2006) Altered synaptic function in Alzheimer's disease. Eur J Pharmacol 545: 11-21. [Crossref]

77. Rodríguez-Martín T, Cuchillo-Ibáñez I, Noble W, Nyenya F, Anderton BH, et al (2013) Tau phosphorylation affects its axonal transport and degradation. Neurobiol Aging 34: 2146-2157. [Crossref]

78. Xie Y, Zhou B, Lin MY, Sheng ZH (2015) Progressive endolysosomal deficits impair autophagic clearance beginning at early asymptomatic stages in fALS mice. Autophagy 11: 1934-1936. [Crossref] 
79. Yu J, Sun M, Chen Z, Lu J, Liu Y, et al. (2010) Magnesium modulates amyloidbeta protein precursor trafficking and processing. $J$ Alzheimers Dis 20: 1091-1106. [Crossref]
80. Li M, Sun M, Liu Y, Yu J, Yang H, et al. (2010) Copper downregulates neprilysin activity through modulation of neprilysin degradation. J Alzheimers Dis 19: 161-169. [Crossref]

Copyright: (C2017 Li Q. This is an open-access article distributed under the terms of the Creative Commons Attribution License, which permits unrestricted use, distribution, and reproduction in any medium, provided the original author and source are credited. 